\title{
STORIES INCARNATE: DESIGNING EMBODIED, INTERACTIVE STORYTELLING EXPERIENCES FOR LIVE AUDIENCES
}

\author{
By \\ Marisa Samek \\ Bachelor of Arts in Economics and English Literature \\ McGill University 2014

\begin{abstract}
An MRP presented to Ryerson University
in partial fulfillment of the

requirements for the degree of

Master of Professional Communication

in the program of
\end{abstract} \\ Professional Communication
}

Toronto, Ontario, Canada, 2020

(C) Marisa Samek, 2020 


\section{AUTHOR'S DECLARATION FOR ELECTRONIC SUBMISSION OF A MRP}

I hereby declare that I am the sole author of this MRP. This is a true copy of the MRP, including any required final revisions.

I authorize Ryerson University to lend this MRP to other institutions or individuals for the purpose of scholarly research.

I further authorize Ryerson University to reproduce this MRP by photocopying or by other means, in total or in part, at the request of other institutions or individuals for the purpose of scholarly research.

I understand that my MRP may be made electronically available to the public. 
Stories Incarnate: designing embodied, interactive storytelling experiences for live audiences, Master of Professional Communication 2020, Marisa Samek, Professional Communication, Ryerson University

\begin{abstract}
Today's audiences are no longer content to passively consume entertainment but are seeking interactive experiences where they have agency to participate more actively. While there has been substantial innovation in entertainment genres that utilize digital media, providing interactive experiences for live audiences remains an ongoing challenge. This project presents an informal evaluation of a proof-of-concept which seeks to engage a seated audience in an embodied, interactive storytelling experience during a live circus performance where the audience can experience agency and communion. Building off Beach Ball Games for Orchestra (Delapierre 2017), where the audience used a large beach ball to play a Pac-Man-style game on a screen at the front of a concert hall, we prototyped an interactive clown show where the audience's ability to collaborate affected the ambient media, the performer, and, by extension, the outcome of the story.
\end{abstract}




\section{ACKNOWLEDGEMENTS}

Thank you to the following people for all the support in the development, creation, writing, and presentation of my MRP:

My two supervisors, Ali Mazalek and Joanne DiNova, my stellar collaborator Tudor Tibu, Louis Etienne Dubois from the Future of Live Performance Lab, our collaborators from Cirque du Soleil and 4U2C, the graduate program director, Matt Tiessen, and the program administrator, Mauro Chiera. The students from the SynLab for their ongoing input and support.

My roommates, including my younger sister, and my friends who supported me with the clown development, filming the project, attending the proof-of-concept performance and for providing invaluable feedback. 


\section{TABLE OF CONTENTS}

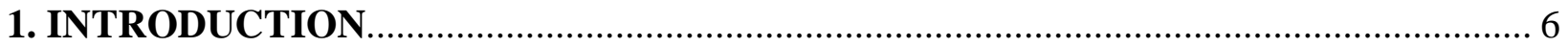

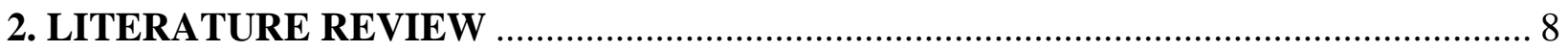

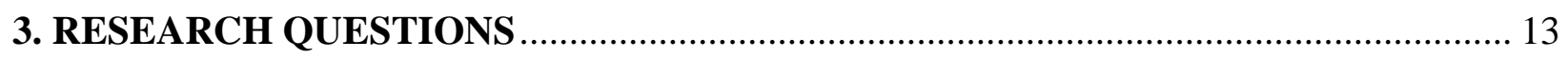

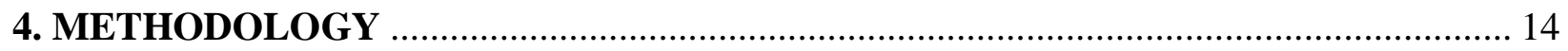

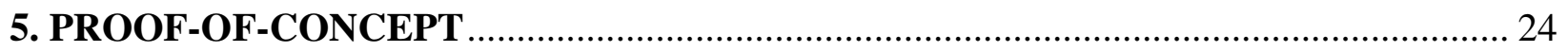

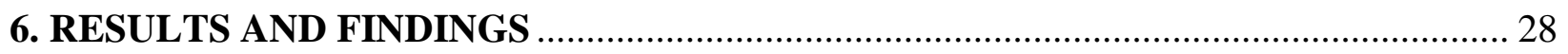

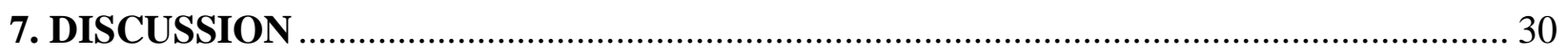

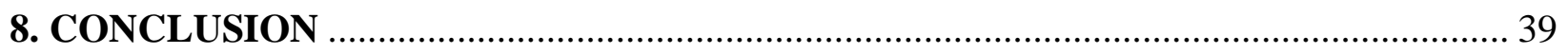

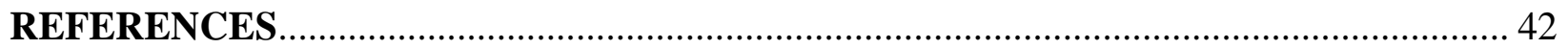




\section{INTRODUCTION}

In his essay on "Audience Participation and the Theatre's Role in the Age of PostPostmodernity", Patsalidis (2013) references culture critic Alan Kirby to suggest that "if a person who grew up in the 60s and 70s still watches and listens, as before, a twenty-year old clicks, surfs, chooses, downloads and deletes; and by doing all this, s/he feels free, autonomous, inventive, expressive, empowered, independent (Patsalidis 2013, para. 2). Kirby (2006) succinctly demonstrates that the way in which we interact with the world, with text, with media has profoundly shifted from that of passive ingestion to active consumption. Not only can we choose our media diets (rather than relying on the same old 24 channel buffet), but we actively engage with the media through various interactive means. While traditional forms of entertainment (television, music, radio, film, etc.) have undergone profound transformation - the migration from the single channel to the many, from the centralized to the decentralized, from the viewer to the user - how has live performance changed? Where does live performance land amidst a world that is increasingly mediated?

It is no surprise that the current trend in live entertainment is to provide the audience with an experience, but not with the sensational experiences of the festivals and tours of the early musicstreaming era, but of experiences that are values-oriented and meaningful. Echoed in famed stage designer Es Devlin who sees "the auditorium as a mass congregation" (Mind-blowing sculptures that fuse music and technology 2019) or in the mission and vision of the premier psytrance festival, Boom, whose intention is to "enable a state of ultimate unity - Oneness" (Boom 2020, "Vision", para.7), today's audiences, more than ever, want to experience the sense of togetherness that has been, as McLuhan prophesied, simultaneously amplified and amputated in the social media age. With these two trends poised at the helm, new audiences are seeking 
both a sense of togetherness and an ability to participate in the way that has become commonplace for them to do so. The third trend emerging within this hyper-mediated reality is the re-introduction of the human body as the original intermediary between our external and internal worlds. Researchers in human-computer-interaction have been investigating embodied approaches to technology basically since the advent of computers. Other industries entertainment, gaming, media production - have started to catch on within the last decade. Within this context, how can we create an embodied, interactive experience for a live audience that provides both the sense of communion and agency?

This project, funded by a MITACS Accelerate grant in partnership with Cirque du Soleil Entertainment Group, seeks to address this challenge by presenting a proof-of-concept that engages a live audience in an embodied, interactive storytelling experience using body-tracking technology. Traditionally, when audiences attend live performances, their bodies are often completely idle or engaged in gestures such as clapping, head banging, waving that do not impact the narrative of the performance in a meaningful way. Some recent work has explored how audiences can interact with a performance through mobile devices, however screen-based devices risk distracting the audience from the on-stage performance and their current design does not encourage a more embodied engagement with the experience. Our proof-of-concept was guided by the research questions: what kind of interaction would provide an audience attending a live circus performance with a sense of communion, in that they can experience a sense of togetherness, and a sense of agency, in that their participation contributes to the development of the narrative in some meaningful way? Follow-up questions included: What types of gestures, technologies, and narratives would be most conducive to this aim? We drew from research in interactive theatre and performance, group facilitation, interactive media, and human-computer 
interaction. Our contributions include a proof-of-concept and a series of design considerations regarding the themes of communion, agency, and context, including more specific topics such as community-oriented narratives, communion-focused gestures, and performer/technology responsiveness.

\section{LITERATURE REVIEW}

Live performance has always elicited audiences to use their bodies to participate in the performance - either as a by-product of being immersed in the experience (e.g., clapping to demonstrate appreciation) or as a component of the work (e.g., shouting during a flamenco performance to add to the musical landscape and encourage dancers/musicians). In Choreographing Empathy (2011), Foster explores the relationship between performer and audience, tracing the history of the terms "choreography", "empathy", and "kinesthesia" to discuss how emotion is transmitted from the body of the performer into the body of the audience. While live music concerts may conjure up images of audience members clapping or head banging, these actions do not necessarily impact the narrative or storyline. One notable early example of the audience engaging their bodies to impact the outcome of a live performance is the pollice verso - the audience turning their thumbs up or down to determine a gladiator's fate at the finale of a match.

Audience interaction has been explored much more extensively in theatre and performance art than in mainstream live performance. Audiences can be co-creators of a theatrical performance for both artistic purposes (e.g., Punchdrunk's Sleep No More) and political ones (e.g., Boal's Theatre of the Oppressed). Other examples of audience participation occur in film (such as Kinoautomat (1967)), sporting events, and live musical performances. The literature on music festivals suggests ways in which audiences co-create the performance in a 
way that may have a transformational effect. Berkers and Michael (2017) discuss the ritualistic quality of music festivals, likening these events to religious ceremonies (that bring about Durkheim's “collective effervescence"). Festivals that feature live performance can foster "collective sentiments; integrating attendees into a "festival tribe"”. In doing so, these experiences link the aesthetic with the social, resulting in a sense of collective identity and meaning.

Given the limitations of live performance (e.g., large venues, seated audience members, choreographed segments), integrating interactive technology with live performance is a fairly nascent area of research. Carpenter (1991) conducted one of the first experiments in this field providing audience members with a paddle that had red and green sides. Through trial and error, audience members came to understand that by collaboratively selecting the red or green side, they could control a game of pong being played on the large screen at the front of the room. Breggler et al. (2004) conducted a similar experiment where 4000 audience members hit several helium-filled beach balls around an auditorium in order to control the digital balls displayed onscreen at the front of the room. These experiments are interesting for several reasons: 1) they engage audiences in using their bodies to interact with something at the front of the room; 2) without words, audiences figure out the rules of a game or of the interaction; 3) audiences, as a group, begin to collaborate in order to complete a task. These experiments provide an example of Beau Lotto's (2019) proposition of a correlation between live performance and prosocial behaviour.

More recently, artists and researchers have explored audience interaction through mobile devices. This includes using mobile phones to create soundscapes (Oh et al. 2011) and musical performances (Dialtones 2001), using texting and social media data to generate visualizations 
and sound (Tweetdreams 2010; Weitzner et al. 2012; Ceratto-Pargman et al. 2014; Won Lee et al. 2019), and more commonly, using mobile devices for polling or sourcing questions during Q\&A sessions (Teevan et al. 2012).

Despite the possibilities for participation through mobile devices, this research is more interested in how audience members can use gestures created by their bodies in order to interact with the performance. There are not many examples of computer vision technology or wearables capturing audience movements and using this data to impact the performance in real-time, either by manipulating the set, the lighting, or the performers themselves. Some examples include Montreal-based company PixMob which has developed a portable transmitter that allows the performer to illuminate the LED wristbands of different audience segments and PixMob wristbands can be used to generate engaging lighting effects from the audience. Tomitsch and Aigner (2004) developed sensors that measure the clapping and cheering of spectators at sporting events, which can be used to provide feedback about scoring, but neither of these examples affect the event in real time. Hassib et al. (2018) suggest that audience sensing and feedback systems such as on-body sensors (e.g., wristbands, heart rate monitors, glasses) as well as environment sensors (video capture, microphones, etc.) can provide more engaging audienceperformer interactions.

Dourish (2004) suggests that meaning arises through our interaction with the world around us and that interaction arises largely through an individual's body movements and the body movements of others. This is particularly true of performances, such as circus and dance, where movement, gesture and body language (usually) outweigh verbal expression and are therefore critical components from which the audience derives meaning. The audience understands the meaning through the performers' gestures, ambient media (such as lighting and 
sound), and props. Therefore, this research posits that while the audience derives meaning from movement, that audience members would be more engaged if their bodies were also moving. Drawing from Lakoff's (1987) theory of embodied schemas and embodied metaphors, Tan and Chow (2018) provide a framework for designing embodied interactions using ambient media. Similarly, Bilda, Edmonds and Candy (2008) provide guidelines for designing creative engagement with digital systems. While both guidelines and framework are derived from and applied to the context of public spaces or art galleries, they still provide relevant design principles for large-scale audiences such as bringing attention to the importance of considering the emotional, sensual, compositional, and spatio-temporal components of the interaction and aligning real-time feedback with embodied metaphors. Maynes-Aminzade et. al (2008) posit that coming up with engaging activities is a greater challenge than developing the relevant technology. To that end, they provide design guidelines that are of a much more practical nature, such as recommending that experience designers vary the pace of the activity, ramp up the difficulty, and make the control mechanism obvious.

Another area of significance is the rise in interactive narratives in digital media and tabletop role playing games. There are several definitions for "narrative", but Zimmerman's definition (2004) is succinct and straightforward: there is an initial state, something changes, and then some insight is derived from how things have changed. "Interactivity" also has several definitions. Zimmerman's model accounts for cognitive, functional, explicit, and metainteractivity. Cognitive refers to the mental activity of responding to a narrative, functional refers to the physical actions necessary to engage (e.g. turning pages), explicit refers to actively making choices that affect the narrative, and meta-interactivity refers to interaction outside of the narrative. According to Gupta, Tanenbaum and Tanenbaum (2019), most interactive games 
address narrative interactivity at the level of plot structure. Their project, Shiva's Rangoli, seeks to challenge this trend by providing an interactive experience that allows the participant to change the emotional tone of the story, which, in turn, impacts the narrative, but not the plot. In Harley et. al. (2016) researchers develop a framework for looking specifically at narratives that include tangible experiences. This framework assesses whether or not the user has a choice over the narrative elements and/or sequence, the interactors positioning along the scale of internal/external and ontological/exploratory (Ryan 2001), the function of the tangible objects, what types of media are included. Brenda Laurel (1991) provides a model which characterizes interactivity by the following three criteria: 1) the frequency of interactivity, 2) range of choices, 3) how these choices affect the experience. In Clifton et. al. (2013), researchers created a gesture-based interactive narrative based on an episode of the show Supernatural. In this project, participants determined the outcome of the episode by moving their bodies in response to various cues from the characters in the show. Researchers determined four ways that participants could be prompted to interact: verbal (a character verbally directs the participant); audio-visual (participant is prompted by something in the visual and auditory environment); reactive (a change in the drama causes the participant to react instinctively); and mimetic (the participants copies the action of a character in the drama). This framework provides a useful starting point, especially when paired with the extensive frameworks that exist from the world of table-top roleplaying games for interactive narrative design. The academic research in the field is somewhat new, but there are many informal sites and blogs dedicated to exploring how to be an effective game master, including processes for designing games that avoid "railroading" (the term used for forcing players to select a specific outcome) or "chokepoints" (moments where the narrative 
cannot continue because there is not sufficient information for participants to move the narrative forward) (The Alexandrian, 2008).

\section{RESEARCH QUESTIONS}

Two gaps in the literature were noted: First, in most of the literature on interactive technology for live audiences, the narrative scenario (often some kind of game) is typically a means to test the technology, but not an object of serious consideration in and of itself. The focus for most of these projects (Carpentier 1991; Maynes-Aminzade 2008) is primarily on the development of new interaction techniques or of new technologies. Most of the examples from the literature or from the initial brainstorming phase of the project test the technology using a game where achieving objectives are primary and story or context are secondary or non-existent. On the other hand, in the literature on interactive performance, the technology is often a means to test new narrative structures without considering how the audience's embodied experience of using the technology affects their reaction to or engagement with the narrative. For example, holding up a smartphone or hitting a large balloon are vastly different interactions that result in distinct experiences for an audience member. In its aim to discover new ways for audiences to contribute to the narrative development, this literature tends to overlook the embodied nature of the interaction medium and how this medium contributes to the overall experience.

This research seeks to develop a proof-of-concept that responds to the gaps mentioned above and which also responds to the growing interest in entertainment industries to provide experiences rather than services. As the interest in interactive experiences rises, traditional live performance venues lag behind other more non-traditional performance genres or digital media for providing such experiences. With that in mind, this project sought to create a truly dynamic relationship between performer, audience, ambient media, and narrative - a relationship where 
all of these elements are taken into consideration and designed in tandem in order to ensure continuity to create an embodied, immersive, and interactive experience for the audience where the audience experiences a sense of agency in terms of affecting the narrative.

The guiding research question was the following: What kind of interaction would provide an audience attending a live circus performance with an embodied sense of communion and agency? Communion and agency in that their coordinated efforts both bring attention to the sense of togetherness while affecting the narrative in some meaningful way. Embodied in that the interaction engages the audience's bodies as the means of interaction. Follow-up questions included: What types of gestures, technologies, and narratives would be most conducive to this aim?

\section{METHODOLOGY}

A research-through-design (RtD) methodology was selected for this project. RtD sees the knowledge generated through the design process as worthy in and of itself. RtD involves prototyping and also may include the reflections of the researcher-designers as valid forms of design evaluation (Tan and Chow 2016). RtD scholars nevertheless stress the need for a critical assessment of the process and of findings that are meaningful for the research community at large (Hook et. al. 2013; Stappers and Giaccardi 2014). In addition, RtD seeks to produce objects or experiences which concretize theory and where the process of concretizing said theory can be assessed and analyzed in order to evince certain practices or themes that may generate insight for the greater design community (Gaver and Hook 2017). Further, the aim of this project is generative rather than explanatory, seeking to generate further considerations for the design space of embodied, interactive live performance experiences. 
The research plan was executed as follows: prior to the outbreak of the pandemic in Canada, the researchers engaged in a co-design process with the partner organization in order to ideate, brainstorm, outline design goals and, finally, formulate a general design concept. The research team at Ryerson University's Synaesthetic Media Lab then hosted a series of design workshops, one of which took place in the lab before the pandemic, the second which took place virtually, and the third which was hosted in the primary researcher's basement. Finally, the primary researcher held a proof-of-concept run-through of the performance in her basement with 9 spectators, 8 of which were audience members and 1 who was an observer.

This research project weathered several changes in plan due to the pandemic and Cirque du Soleil Entertainment Group's subsequent layoffs and bankruptcy. The initial research plan included working more closely with the partner organization, 4U2C (a subsidiary of Cirque du Soleil Entertainment Group), and a user study of the proof-of-concept during a live performance with roughly 150 spectators.

\subsection{Ideation Phase and Design Goals}

Drawing from the literature and a participatory co-design process with our partner organization, we formulated the following design goals for the interaction:

- Uses movements that the audience would do naturally

- Requires minimal explanation

- Requires audience coordination

- Can be played seated

- Could potentially be scaled up for a Cirque du Soleil audience of 60,000 attendees

- Accounts for varying levels of audience care and the discrepancies in willingness to participate 
During our ideation phase with the partner organization, we chose to base our concept off of Beach Ball Games for Orchestra (Delapierre 2017), a former project of our partner firm, where the audience attending a performance of the Montreal Symphony Orchestra used a large beach ball to play a Pac-Man-style game on a screen at the front of the concert hall. In Beach Ball Games for Orchestra, however, there was no overarching narrative, the game did not inform any narrative arc, and the musical performance had no relationship to the audience interaction or game play. Our research sought to address these shortcomings by better integrating the elements of performance, i.e. still using balls to drive the action, but, this time, contextualizing the experience within an overarching narrative that will be driven by the audience's interaction with the balls, a live performer, and ambient media.

We chose to base our work off of this project for several reasons. On the technical side, a large ball is easier to track in a dark performance hall compared to our initial idea of tracking the audience's discrete gestures. On the interaction side, the tangible object gives the audience a reason to reach up and move their bodies and could potentially act as a means of facilitating collaboration. On the narrative side, the ball has many possibilities to act as a diegetic object, bridging the world between audience and performer. Finally, we decided to create the experience around a clown show given that these segments during Cirque du Soleil shows provide more opportunity for improvisation and input from the audience, versus the tightly choreographed acrobatic segments.

\subsection{Design Phase 1}


As per Maynes-Aminzade et. al's (2008) design consideration "focus on the activity, not the technology", design phase 1 consisted of focusing on the developing the activity that the audience would be engaged in during the experience. We wanted to get a sense of what kinds of actions we might want audience members to complete using the balls, of the opportunities and challenges of using balls, of how many balls the audience could manage at once, and of how to incorporate the activity with an engaging narrative.

\subsubsection{Design workshop 1. We invited approximately 10 students from our lab (all university} students without any prior knowledge of the project) to participate in an informal design workshop as a preliminary means to explore how the balls might work as both a medium of interaction and a narrative element. The researcher acted as a performer, standing in front of the seated audience of participants, and told a story ABOUT the balls being "star seeds" that could help regenerate a decaying planet. In the workshop, various locations in the room were tagged with different colours, representing different ecosystems which required revitalization. Depending on which colour the ball was, the audience needed to move the ball to the marker of the same colour. Finally, the audience needed to get the balls back to the front of the room.

We found the balls satisfied some of the design criteria in that our game required minimal explanation and used movements that the audience would engage in naturally. Nevertheless, the audience members found the narrative context insufficient to keep the game interesting. They spoke of wanting to have more story and for the performer at the front to be involved in some interesting activity other than simply facilitating the game play. We noted the need for a more diegetic design process (Gupta et. al. 2019) in order for the experience to be more immersive and engaging. 
4.2.2. Results from Design Workshop I. The findings from this workshop were in keeping with some of the design guidelines set out by Maynes-Aminzade et. al. (2008) i.e. ramp up the level of difficulty as the activity goes on and focus on the activity, not the technology. Perhaps the most salient finding from this workshop was the extent to which the activity, or in this case, the narrative, affected the level of engagement and interest. To that end, one question we sought to ask was how we COULD move away from more game-like experiences or "activity" and design an interaction that feels wholly incorporated in the narrative.

\subsection{Design Phase 2}

The findings from the previous workshop encouraged us to shift our focus from the activity (the interaction with the balls) to the narrative context. We sought to create a narrative where the audience's actions would generate different outcomes. In keeping with the environmental theme, we came up with an idea for a story where a clown wants to plant a tree and the audience's actions with the ball affect the weather which, in turn, affect how the tree grows. We initially designed the interaction with the audience's actions as our primary focus, imagining the different actions that audiences could do with the ball and assigning subsequent ambient effects to these actions. For example, one of the balls in our initial design controlled the element of rain and tapping the ball quickly or slowly could produce more or less rain. We sought to create interactions that were more-or-less evident in terms of how the embodied gesture related to the effect. In the rain example, we thought that the tapping of the ball mimicked the spattering of rainfall.

We broke down each component of the experience into respective variables. The variables of the ball included: position (the position in the room), pace (the speed at which the ball was being passed), and gesture (the gesture made with the ball). Variables were broken 
down as follows: position (left, right, centre), pace (fast, slow, still), gesture (pass, tap, hold). We then drew from Clifton et. al.'s (2013) model to ideate on how the performer might respond to the audience's gestures in such a way to facilitate their movements. We simplified the model to include following ways in which the performer could communicate with the audience: mimetic (referring to the performer making gestures that the audience was intended to imitate), communicative (referring to gestures that were explicitly telling the audience what to do), and reactive (referring to gestures that were reacting to the ambient media, thus implicitly communicating a message to the audience). The ambient media was broken down into the following variables: sound, visuals, and lighting.

In this initial design scenario, the audience gestures dictated the outcome of the narrative and we created a spreadsheet to generate a walkthrough of the experience. In this walkthrough, we predicted how the action might unfold according to how the audience might interact with the ball and how the other two components of the experience - the performer variables and the ambient media variables - might react as a result. Moreover, we mapped out the narrative structure based on the different variables afforded by the balls (wind, rain, and sun) and then mapped out the possible combinations of those variables to come up with three different endings to the story.

4.3.1. Design Workshop II. We then hosted a virtual design workshop with 9 participants: 3 professors from performance fields, one in theatre, another in clown, and a third in costume, 3 circus students from the National Circus School in Montreal, and 3 members of our lab. We broke the group into two teams and had each team walk through the performance attempting to describe how the ball's movements would impact the other variables in the narrative and generate a comprehensive story and interactive experience. 
This workshop did not go as planned but, it was, in its failure, a catalyst for the development of the project. Participants failed to fill out the spreadsheet, articulating that they did not have sufficient information about the clown. They asked questions such as: "What kind of clown is it?", "Why is the clown planting the tree?", "Is it a leader clown or a follower clown?", "Does the clown know that the audience controls the weather or is it also a discovery for him?" From these findings, we then focused on developing the clown and building the narrative around the clown's character. In the initial research plan we had intended to work with a professional clown, however, the findings from this workshop coincided with the social distancing protocols. Without any clear sense of how long the restrictions on gathering might last and the project timeline, the research team decided that it would be best for the lead researcher, who has some modest experience in theatre and dance, to be the clown in the proof-of-concept. The lead researcher met with the clown professor to receive some guidance on how to go about creating a clown. The professor recommended "playing" with the intention of improvising a narrative arc using only movement, gestures, and facial expressions, while also filming the clown play in order to start developing a coherent clown character. The outcome of this phase in the design process will be discussed more in depth in the Implementation section under the heading “Character Design and Narrative Design”.

4.3.2. Results from Design Workshop II. This meeting's spectacular failure was perhaps one of the most useful experiences in the entire process. There were four main results that emerged from this design workshop. Perhaps the most important was the emphasis on the character. As technology designers, we had been thinking about the experience from the perspective of the ambient media, audience gestures, and narrative structures. These workshop participants helped 
us to reframe our process, demonstrating that the performer, the character, is paramount in that it is through the character that the story is essentially being told.

The second crucial finding was the decision to design an interaction which tracks the audience for its capacity to collaborate and cooperate as a means of creating a more direct link between the audience gestures and the unfolding of the narrative. The third result, which is intertwined with the second, was the decision to write a narrative in which the audience is not simply contributing to, but in which they are, in fact, a character.

The fourth result was the development of a model to track cooperation and collaboration. Bearing in mind Beau Lotto's study (2019) on the positive correlation between awe and prosocial behaviour, we developed a model that tracked collaboration by facilitating the audience to engage in gestures that are based off of the principles that govern good conversation: allowing everyone to speak (i.e. passing to everyone), changing the pace of the conversation (i.e. passing fast and passing slow), and pausing to listen (i.e. holding the ball in a specific location).

\subsection{Design Phase 3}

Given the results from the second workshop, we developed a more elaborate narrative in which the audience needed to work together in order to revive a forest. We then developed a set of gestures that we wanted the audience to complete in order to track their effectiveness at cooperating with one another.

4.4.1. Design Workshop III. This workshop consisted of testing a first iteration of the entire experience with 3 participants, none of whom had any prior knowledge of the project. The setup consisted of three white sheets at the front of the room onto which a stop motion video of a forest either growing or decayed was projected. The clown emerged from behind the sheets and mimed 
a story about arriving back to their enchanted forest after a long journey only to find it completely bare. The clown tries to revive the forest using magic but is unsuccessful. All of a sudden, the clown notices a magic seed (the ball) on stage right. The clown approaches the magic seed and as soon as he picks it up, the seed tells him that he must work with the audience in order to bring his forest back to life. The clown, certain that the humans are to blame for the destruction of his homeland in the first place, reluctantly offers the seed to an audience member and then begins planting trees.

In the first video sequence, the position of the ball appears on the screen as small dots, which are meant to represent the planting of seeds. Once all the audience members have received the ball, the video switches to the next segment of the trees either growing or decaying based on how the audience collaborates with one another (i.e. the frequency and speed of passing) and/or reacts to the clown's actions (i.e. their movements are responding to the bids made by the clown).

Given that there were only 3 participants, they each passed to one another, explored different paces of passing, and did respond to the clown's bids for passing quickly, slowly, or holding the ball still. In the first run-through, the participants were successful in restoring the forest to its full potential. In the second run-through, however, participants were more experimental with their movements, were not as cooperative with the clown's requests, and, ultimately, were not successful in restoring the forest. Participants found the experience enjoyable, engaging, and meaningful, but were uncertain about how their movements with the ball affected the ambient media.

4.4.2. Results from Design Workshop III. We noted the need to create a clearer connection between the audience movements and how they affected the ambient media. This 
connection needed to be clearer for both the audience and for the researchers. One limitation was that our wizard of oz prototype relied on one of the researchers to play the video either forward or backwards (towards growth or decay) depending on the level of audience cooperation and collaboration. What was insufficiently clear was how the researcher would assess these two elements. The first was easier to assess because cooperation referred to the extent that the audience responded to the clown, which the researcher could observe by watching whether or not the audience acted in the way the clown asked them to. The second, collaboration, was more challenging to assess without creating a model to define what constituted collaboration. Given these findings, we adapted the narrative by splitting it up into four phases and assigning an action for the performer to each phase and a related action for the audience. The four stages for the performer were dig, plant and cover, do magic, and water. They related to the respective actions for the audience: pass to everyone, pass slowly, pass quickly, and hold in a specific location. Each stage corresponded to a different video segment. If the audience made the correct gesture, then the video would progress to the next segment. If they did not, then the video would continue to decay into the previous segment. Using this model allowed for the performer to facilitate the audience's gestures in a more natural sense because the gestures that the performer wanted the audience to do were encoded in his own. For example, for passing slowly, the performer mimed the action of planting the seed in a very slow and careful way. For the passing fast gesture, the clown swirled their magic staff faster and faster in order to encourage the audience to quicken their pace. To summarize, Design workshop III highlighted the necessity and the challenge of making the control mechanism obvious, i.e. making the relationship between audience gestures and ambient media as clear as possible. Further, it also evinced the importance of creating 
sophisticated props, costume, and makeup in order to set the context and immerse the audience in the world of the story.

\subsection{Proof-of-Concept Showcase}

The findings from this workshop helped us to develop a more concrete model for audience participation which mapped onto the performer's gestures and the greater narrative, all of which were tested during a final proof-of-concept showcase with 8 audience members and 1 observer. We ran the proof-of-concept like a formal show, none of the audience members had any prior knowledge about the experience. Audience members arrived and were ushered into their seats. Given the ceiling height and the placement of the projector, we seated 4 audience members in chairs and 4 on a cushion in front of them. We intended to run through the performance 3 times and hold an informal discussion after each run through. The results from the proof-of-concept showcase are described in the Results section.

\section{PROOF-OF-CONCEPT}

\subsection{Character Design, Narrative Design, and Interaction Design}

The clown character, the narrative, and the audience interaction gestures went through several iterations. In the first iteration, the narrative was about a clown who wanted to plant a tree to shade himself from the hot sun and the audience could control elements such as wind, sun, and rain which would impact the growth of the tree. After the second design workshop, we expanded the story to be about a clown who wants to sing happy birthday to one of his stuffed toys, but cannot do so because he is too hot. He decides to plant a tree and, similarly, the 
audience's gestures impact whether or not the tree grows, and, subsequently, whether or not he ultimately celebrates his furry friend's birthday.

As the researcher spent more time improvising and developing the "planting a tree to sing happy birthday" story, questions arose not only about why the clown wants to plant a tree, but why does the audience want to participate? In response, we shifted the narrative to one where the audience was not only participating in the unfolding of the clown's story, but where they were characters in the same story. This realization led to the inspiration to depart from previous projects in this field where audience gestures were tracked in a linear way, mostly tracking position to, instead, conceive of an interaction that sought to take into account the audience as an aggregate and to track the audience's cooperative or collaborative capacity, similar to the installation Illumina where participants wore heart sensors which fed the data into an illuminated sculpture which beamed more brightly as participants' heart rates became more in sync. The synthesis of these two ideas - an environmental-based narrative where the audience is a character and an interaction where the audience is tracked as an aggregate - culminated in the philosophical underpinning of the integral relationship between human beings and nature.

With this concept in mind, the final iteration of the narrative tells the story of Verdi, the keeper of the forest, who returns to find his lush home empty and bare. Crestfallen, he tries to revive it using his magic, but finds that he cannot do so. He finds the mother seed who tells him that he must rely on humans to help him. We changed the story from the audience controlling the elements that affect the growth of a single tree to the audience needing to pass the mother seed amongst each other to revive an entire forest for the reasons mentioned above as well as a couple other reasons. First, we were concerned about the logistical complexity of passing two balls around with different effects, and how these dynamics would impact split attention (the need for 
the audience to split their attention between the ball play, the ambient effects, and the narrative). Second, drawing from Tan and Chow's (2016) model of embodied schemas, we thought it would be a more engaging and embodied experience for the audience to be controlling the aspect of the performance that is at the centre of the action. Further, the limitation of telling a story without speaking inspired the researcher to rely on sound in order to assist in setting the scene and explaining both the context and providing instructions without being overly explicit. The researcher created a soundtrack to the performance remixing segments of a speech by Canadian Indigenous scholar, Jeanette Armstrong, where she extrapolates on the relationship between how we treat one another and how we treat the land.

We then used the four interaction and narrative stages discussed above (pass to everyone, pass slowly, pass quickly, and hold) and mapped them onto different stages that Verdi would engage in to replant the forest. He dug the holes for the seeds, planted and covered them, blessed them with his magic staff, and then watered them. The forest responds to the extent to which the audience is able to coordinate their actions and cooperate with what Verdi is both implicitly and explicitly asking them to do. When the audience cooperates and collaborates, the forest grows. When they do not, the forest decays. We created three endings which depend on the extent to which the audience can achieve these goals. The first ending is the forest is fully restored, the second is that the forest is partially restored, and the worst outcome is that the forest does not grow back at all. We then scripted three different ways that Verdi would react depending on the outcome. In the first, he is overjoyed and thanks the audience. In the second, he is slightly disappointed and returns to work planting trees. In the final one, he is devastated. He turns to leave, head bowed and staff dragging on the barren forest floor, but, right before he disappears 
forever, he looks at the audience and leaves them with the seed, a gesture that there may still be hope for them to try again.

\subsection{Technical Design and Wizard of Oz Prototype}

Given the project timeline and the logistics of tracking the ball in the researcher's basement, we opted to create a Wizard of Oz prototype for the final showcase. Wizard of Oz prototyping is useful for presenting concepts in a low-fidelity format that allows for rapid prototyping. We created various video segments to show the planting of the seeds and then the growing/decaying of the forest using Adobe Illustrator and ISADORA 3.0 from TroikaTronix. In our version, one of the researchers manually tracked the position of the ball using the mouse by observing where the ball was located in the audience. For the forest growth/decay segment, he observed how the audience was cooperating and collaborated and played the video either forward or in reverse, respectively. In a more polished version of the experience, we imagine that the ball would be tracked using infrared tracking.

Findings from this design workshop demonstrated that participants could tell how their actions affected the ambient media for the first stage, some even thinking that there was a sensor in the ball but could not understand how to affect the narrative for the subsequent stages. In order to make it easy for the researcher manning the tech to assess the quality of cooperation or collaboration, we cut the video of the forest growth into 3 segments and, as explained above, each segment corresponded to a different phase in the performer's actions. We timed each section to roughly correspond to the amount of time it would take for the performer to complete that action and played that video segment in reverse if the audience did not cooperate or collaborate sufficiently. We also built a blackbox theatre in the researcher's basement in order to 
create an environment where the experience could accommodate an audience, a video projection, and could be filmed.

\section{RESULTS AND FINDINGS}

This section presents a summary of the results from the proof-of-concept performance and informal discussion. We do not make claims about our process being necessarily repeatable, but rather aim to uncover interesting themes and findings that may help to expand the contours of this design space.

\subsection{Results from the Proof-of-Concept Performance}

Given certain technological glitches, we only ran through the performance from start to finish once. We held an informal discussion after the first run-through. We then showed the audience the different endings and explained how the whole concept works. We sustained several technology challenges and were not able to sufficiently respond in real-time to how the audience interacted with the ball, the technology was not sufficiently responsive for the audience to understand how their actions affected the ambient media. Nevertheless, the project was very well received. Participants found it enjoyable and engaging. In our informal discussion, we asked questions relating to the following themes: engagement (was the experience enjoyable? What could be done to enhance it?); functionality of the interaction (was the experience understandable? Was it too challenging or too easy? Was it evident what the ball was controlling?); social experience (Did participants want to cooperate? How did they want to engage within the group? Did they experience a sense of communion and/or agency?); narratives (how else could the story change? What other types of narrative might work for an 
experience like this?); and future uses (what other environments or contexts could participants envision for this type of experience?).

\subsection{Findings from the Proof-of-Concept Informal Discussion}

Participants provided useful feedback on several elements of the performance. They all found the experience engaging and immersive and spoke positively of the "community engagement aspect" (P3). One participant explained, "I felt like we were building something together even though I was aware that I was watching a performance” (P2). Moreover, participants spoke positively of the embodied nature of the experience, i.e. the use of an object that audience members could hold and how that drew them in (P2, P3, P7). When asked about narrative and which narratives could work well for these types of experiences, audience members found that the narrative we selected was both easy to understand and sufficiently nuanced. Several audience members enjoyed the community-oriented nature of the narrative and suggested that other community-oriented narratives could be effective such as stories about working together to clean up the ocean, stories about communities raising a child, or stories about the importance of community for responding to mental health issues.

In terms of the implementation and functionality, there were some discrepancies in the participants experience. All participants understood how their gestures affected the ambient media in the first segment of the video, but only a few of them sensed any connection with their gestures and the ambient media in the subsequent video segments. Nevertheless, one participant found the pace and learning-by-doing process to be engaging and meaningful. He noted, "The more we participated we, I, slowly learned what you were trying to convey and what was going on. That humans had to be part of it and that we had to work together" (P6). 
Participants tended to agree that the social dynamics of the experience might be specific to the size and intimacy of this performance. They spoke of wanting to participate and cooperate, one participant even expressing fear of "ruining the performance" (P3) if she went against the grain. On the other hand, one participant noted that the "discovery moment for me [the discovery that we were controlling the ambient media] was when I broke the path" (P7).

Participants had several ideas about how to scale the experience and how to improve it. They suggested having several balls, perhaps even of different sizes. They also discussed increasing the immersive quality of the experience by projecting the ambient media behind the audience or on the ceiling of the big top (P7). Nevertheless, when asked about split attention and the challenge of focusing on the interactions with the ball, the ambient media, and the performance, most participants agreed that it was challenging to focus on all three things at once.

Overall, participants found the experience well-executed, engaging, innovative and meaningful. They enjoyed the implementation of the performance elements such as the acting, the props, the set, and the soundtrack.

\section{DISCUSSION}

In this project we sought to develop a proof-of-concept of an interactive, embodied experience for live audiences that 1) fostered a sense of communion amongst the audience and 2) a sense of agency. In order to develop an experience which fulfilled these two criteria, we needed to evaluate which narratives, technologies, and gestures were most conducive to fulfilling our goal. Our intention in creating such an experience is a response to the growing demand for participatory experiences in live performance and our attempt to innovate on the previous work in this field, most of which have focused more on game-play than on creating a comprehensive 
experience where the audience's gestures are contributing to how the narrative of a live performance might unfold.

In the discussion we bring up some main themes that help to expand this novel design space by both expanding on design guidelines from previous works and generating some insights from our own process. The themes were generated from our design process as well as from the proof-of-concept performance and informal feedback from audience members. Our findings can be organized under the three main themes: Communion, Agency, and Context. Each theme has several sub themes: Community-Oriented Narratives and Audience as Character, Social Dynamics, Gestures for Generating Collaboration and Cooperation, Responsiveness: Technology and Performer as Facilitators, Breaking the Path to Understand the Path, Clarity of Intention, and Scale and Setting.

\subsection{Communion}

Communion refers to a group's ability to experience a sense of togetherness and social cohesion. It is an essential quality of close groups and communities. Although communion may be present at live performance events in that audience members are physically in communion i.e. co-located in the same environment, the feeling of being in communion is seldom made explicit. We found these elements to be important to consider when designing an interactive narrative experience for a live performance which seeks to elicit a sense of communion amongst the audience.

\subsubsection{Community-Oriented Narratives and Audience as Character. Our choice of} narrative was particularly effective at fostering a sense of community. We spent a significant amount of time wrestling with different narrative ideas and ultimately settled on one where the audience is not only a participant in the experience, but they are also a character contributing to 
the unfolding of the action. In our story, Verdi, the keeper of the forest, must enlist the help of humans in order to restore the environment to its original grandeur. While asking participants to create an avatar or become a character in the story is a hallmark of interactive experiences (from video games to tabletop role playing games), it is much less common for an interactive experience to position an entire audience as a character within the story. Participatory theatre, however, such as Theatre of the Oppressed, demonstrates how giving the audience the opportunity to intervene in the unfolding of the narrative transforms the experience of being an audience member and of how audiences experience the action. When given responsibility, audiences can shift from being passive observers to active agents.

In our experience, in order to characterize the entire audience as a character, we drew on a community-oriented narrative i.e. a narrative in which a community needs to act in order to drive the story forward. It seems that narratives using environmental themes are well-suited to create community-oriented narratives particularly because of the current awareness around human activity and its effects on the environment. It would be interesting to reflect on what other types of stories could be told using a community as the catalyst for the action. How far can the characterization of the audience go? In our story they were still human (in other words, very little stretch of the imagination was required) but what else could they be? Other human-like characters might be effective (such as wizards and warlocks), but what about animals or plants? Moreover, does the audience need to be characterized as an entity consisting of multiple people or would it be possible to characterize the entire audience as a single entity? For example, could the entire audience play the character of, say, an ogre, or of a single tree?

7.1.2 Social Dynamics. In our proof-of-concept the social dynamics were such that participants wanted to collaborate and cooperate. There was some hesitation to break the mould, 
but breaking the mould was, in fact, a way for the audience to understand that they had agency (which will be discussed below). It seems that the social dynamics depend on the size of the group and of the proximity between the performer and the audience. It is difficult to assess whether or not our findings on social dynamics have any bearing on a Cirque du Soleil audience that can be as many as 60,000 spectators. Nevertheless, the social dynamics are a crucial consideration and one that relies on several factors including audience size, the audience's proximity to the action, the different types of audience members (those who prefer to follow the group versus those who prefer to break from it), the mechanism for facilitating audience participation (including the actual technology, but also the performer's gestures, and the narrative context which tells the audience who they are in the story). The social dynamics is a component that requires further research as there are several factors which can influence it. The findings from our project relied on design considerations from previous projects which encouraged the use of natural movements and activities which require little to no explanation. These proved to be useful in facilitating an effortless social dynamic, one where the audience was able to participate right away. Moreover, we also applied the design guideline of starting with simple movements and increasing the level of difficulty over time. This guideline also proved to be useful in that participants reported experiencing a greater sense of communion as the activity shifted over time. It is possible that as the audience works together, the added complexity of the activity generates a greater sense of shared responsibility, particularly if the mechanisms for facilitating participation i.e. the performer and the narrative context, demand it. As mentioned in the point above, it appears that creating the context has the potential to strongly influence both the audience's willingness to participate as well as set the tone of how they 
participate. One could imagine a context or a clown which elicits a chaotic social dynamic from the audience versus one which elicits an orderly dynamic.

\subsubsection{Gestures for Generating Collaboration and Cooperation. One innovation in our} design, which also presented a significant challenge, was attempting to create ways to track audience collaboration and cooperation. Previous projects have used motion tracking to sense audience coordination to be able to hit a target on a screen (Maynes-Aminzade 2008; Lapierre 2017). In our project, we were curious about what other types of gestures could be tracked. We attempted to track the position of the ball and the change of pace. Moreover, we wanted to track the audience's gestures with the ball in response to the media and to the performer. Our proof-ofconcept was not sufficiently responsive to provide any concrete findings around how to effectively track the pace from a technical standpoint. Nevertheless, the idea to track something other than position is an interesting one that merits further research. In the aim of generating a sense of communion, what other types of gestures or activities might be considered? Further research may be required to discover what types of actions create an embodied sense of togetherness. Is it sufficient for audiences to be engaged in the achievement of a collective goal or are there specific actions that might generate a greater sense of communion?

\subsection{Agency}

Agency refers to the audience's sense of their own ability to affect certain aspects of the live performance. In our case, agency refers to their ability to affect the ambient media, and, by extension, the outcome of the performance. There are several factors which contribute to the audience experiencing a sense of agency. Here we outline two elements that we found might be helpful in designing experiences that elicit a sense of agency. 
7.2.1 Responsiveness: Performer and Technology as facilitators. In our example the control mechanism i.e. the way in which the audience controlled the media, was not sufficiently obvious which made it difficult for the audience to understand how their gestures were affecting the performance. This finding leads to the importance of responsiveness of the technology and the performer in order for the audience to experience a sense of agency.

One way that the audience can experience agency is the way in which the performer facilitates the interaction. We adapted a model from Clifton et al. (2013) consisting of communicative gestures, reactive gestures, and mimetic ones. Communicative gestures were employed to bring the audience's attention to what the performer was doing, mimetic gestures were primarily used in that the clown conducted their gesture at a certain pace as a way to convey the pace that they would like the audience to pass the ball around, and reactive gestures were used to show the audience whether they were engaging correctly or incorrectly with the ball. These gestures were easy for the audience to notice and respond to, given their proximity to the performer. Moreover, the proximity to the performer appeared to create a sense of social pressure to conform. It would be important to consider the scale of the performance in order to assess which kinds of gestures would be most effective at facilitating the audience's actions. Further, in our scenario, the clown played a significant role in facilitating the audience's actions and the most successful outcome was contingent on the audience's ability to read the clown's cues. It could be interesting to create an experience where the audience is given freer reign to explore the opportunities afforded by the interaction, but this type of interaction might require a very responsive media environment, i.e. one where the ambient media responds almost instantaneously to the audience's actions. This brings up the challenge of tracking something like 
change of pace. One thing to consider is how to design a media element which responds to the pace at which the ball is being passed.

7.2.2 Breaking the path in order to understand the path. One participant in our proof-ofconcept performance spoke about the magic of the moment when he discovered that his actions were affecting something on the screen at the front of the theatre. While this moment of discovery is interesting in and of itself, and particularly how that moment may happen at different times for different audience members and how it contributes to the sense of engagement in the experience, what is particularly fascinating is how that moment occurred for this audience member. This participant explained that they discovered their agency by straying from what the other audience members were doing (passing the ball in a circle). Once he moved the ball around instead of passing it to the person next to him, he realized that his actions were having an impact on the screen. This moment also signalled to other audience members that the ball was being tracked and that they too had agency in terms of determining what was being displayed on the screen.

This finding opens up other questions about how to facilitate the discovery of audience agency. It is interesting to consider ways in which it might run counter to the desire to create a sense of communion. If the audience members need to break from following the herd in order to understand that their actions are actually doing something meaningful, what is necessary to design an interaction that allows for both communion and agency to be present? In answering this question, there are a few elements to consider. One element is the way in which the control mechanism is introduced. In our proof-of-concept, the clown did not play with the ball to show the audience what to do, but immediately threw it into the audience, leaving the audience to 
figure out how to use it themselves. One might imagine a scenario where one clown, or several clowns, play with the ball as a means of teaching the audience what to do (or what not to do). This configuration, however, might not yield that magic moment of surprise. It would, however, provide the audience with a more immediate sense of agency since they would know that the ball controls something and thus could then be more readily prepared and facilitated. In another scenario, the audience might be given free rein to play with the ball for a greater amount of time until they realize that their actions are being tracked. The challenge then, which is what we experienced, is how to move from a more individual-based experience to a more collectiveoriented one? This might require more direct intervention from the clown or a more direct learning example, say, if several clowns at the front of the stage showed the audience what to do. Some answers to these questions might also be found in the research of games and game dynamics which often rely on various cues in order to instruct players how to engage with the medium. One challenge, then, is to maintain the delicate balance between all of these factors: the individual moment of discovery with the willingness to participate with the group and the attention towards achieving a goal without losing the integrity of the narrative.

\subsection{Context}

Context here refers to everything in the environment where the interaction occurred, i.e. the narrative, the performer, the sound, and the physical location. It appears that context plays a crucial role in the experience of the audience and in the success or failure of the interaction. The following factors appear to be important to consider with regard to creating an effective context:

\subsubsection{Clarity of intention. Although this may seem evident to those who work in}

performance, for interaction designers it may be easy to overlook how each element contributes 
to setting the tone of the experience. In a performance context, particularly one where a story is told non-verbally, the audience is scanning the environment for cues in order to understand the action. In this milieu, every element conveys a message that the audience is trying to interpret in order to make sense of the experience. To that end, the success of these types of experiences, particularly in an experimental context, may be impeded by not paying enough attention to details such as props, costume, sound, and lighting. While HCI researchers often have to balance project timelines and resources with creating a proof of concept that is "good enough", it is important to note that for experiences which rely more on performance, not paying enough attention to the details could weaken the integrity of assessing the technology accurately because the audience might be too caught up in making sense of an element which has not been sufficiently integrated into the performance. For example, during the third workshop, we had not yet painted the beach ball as "the mother seed". While participants understood the gist of the performance, they did not quite understand how the ball related to the story. Moreover, in the same workshop, the performer's costume was also unfinished, and, similarly, participants had a hard time contextualizing the performer's action, wondering if the clown was a car mechanic rather than a mythical forest sprite. During the final performance, however, the finished costume (a pair of coveralls donned with fake plants) and the ball (painted to look like a seed with a faint impression of an elderly woman's face on it), one participant surmised the entire context almost verbatim to how we had written it up in the script.

7.3.2 Scale and Setting. It is challenging to generalize any of our findings given the scale of our performance. It seems that the dynamics of an intimate 8-person audience show are very different than those in a large arena or circus tent setting. Many elements would change, namely 
the size and number of the balls used, the proximity to the performer, likely the use of screen in order for the audience to see the performer, and the need to create ambient effects that could be visible to all audience members. There are certain elements of the experience that we designed with the scale in mind, such as the gestures that we asked the audience to perform and how we scripted the performers actions in order to facilitate the audience to perform them. It may be important to design these types of interactions with the size of the environment in mind because it can affect many components of the experience. Scale also brings up questions relating to agency and control. With an 8-member audience, the performer can easily follow each audience member and respond to their gestures in order to facilitate a desired outcome. This setup begs the question: what is the maximum number of audience members that a performer can facilitate in a one-to-one fashion? Is it 100 audience members? 1000 audience members? If Beach Ball Games for Orchestra provides any indication about what is possible, it may be that the performer responds not necessarily to individual actions but to the movement of the ball, which is a factor of aggregate movement rather than individual actions.

\section{CONCLUSION}

This paper presented a proof-of-concept for an embodied, interactive experience where audience members collaborated in order to affect the outcome of the performance. This experimental design concept aims to elicit feelings of both communion and agency for a live audience and, although it was tested in an intimate setting with 8 audience members, it is intended to be scaled up for an auditorium or stadium-sized experience. Following a RtD methodology, this proof-of-concept consisted of three design phases, each consisting of one design workshop. Each phase built on a different aspect of the experience, starting with the activity and gameplay, then developing the narrative and audience gestures, and finally testing 
the entire experience in order to tweak certain elements into a proof-of-concept performance. The findings from this project consist of the results from the design process, the proof-of-concept performance, and the informal discussion with audience members which took place during the performance. The findings are not conclusive by any means, but rather provide some points to consider for designing these types of experiences in general.

The main findings can be categorized under the themes of communion, agency, and context. The findings relating to the theme of communion can be summarized as follows: community-oriented narratives and characterizing the audience within the story to be an effective avenue for contextualizing these experiences to elicit communion and agency. The social dynamics of a live audience are complex and can be affected by various factors including narrative, performer, setting, and scale. More work is required to understand how different levels of audience care affect the willingness to participate and how the former may be related to audience size. Regarding gestures for interaction, we developed some gestures that appear to be effective at generating cooperation. Nevertheless, it would be interesting to further investigate the relationship between types of gestures and audience experience. With regards to the sense of agency, there are two points of interest: the first is the notion of the technology and/or the performer facilitating the audience's gestures. Each case, or a combination of both, requires further exploration as they each engender their own affordances. In either case, they both require a high degree of responsiveness in order for the audience to understand how their interactions are affecting the narrative. The other finding of interest is related to the challenge of making it clear to the audience that their actions are having an impact. We found that, although we are trying to facilitate cooperation, the moment of discovery of agency happened when an audience member dared to do something different from the rest of the group. This finding leads to questions about 
the range between chaos and control and the importance of providing audience members with sufficient space to discover their agency in the experience, while also constraining the possibilities so as to ensure a coherent, cohesive experience. Further, the themes relating to context include a recommendation for HCI researchers in general as well as the myriad of considerations that come from changing the scale and the setting of the performance. For the former, we found that each detail selected in the performance (or each detail we forgot to address) greatly impacted the audience's ability to understand the narrative. With performance, particularly non-verbal performance, gesture, costume, props, set and ambient media must all be very carefully chosen in order to convey the intended message. Even when trying to produce a proof-of-concept, any omissions may confuse participants and undermine the experiment. Finally, future work must look at how different settings and, by extension, scales influence all elements in the experience: performance type, narrative, gesture, technology, and ambient media. The logistics of each venue are often unique to its size and what works with an 8-person basement is certainly not the same as what will work in a 60,000-person stadium. That said, our future work intends to build out the technology in order to test the tracking of the ball for a larger audience of roughly 150 people. We hope that by looking at slightly larger audiences and venues that we will be able to develop a set of guidelines that will be more applicable to traditional Cirque du Soleil venues. 


\section{REFERENCES}

Aigner, W., Tomitsch, M., Stroe, M., \& Rzepa, R. (2004). Be a judge!: wearable wireless motion sensors for audience participation. Extended Abstracts of the 2004 Conference on Human Factors and Computing Systems - CHI '04, 1617. https://doi.org/10.1145/985921.986173

Berkers, P. \& Michael, J. (2017). Just what is it that makes today's music festivals so appealing?.

In: Peter Koudstaal (ed.). Music brings us together: Music \& Art festivals. Den Haag:

Uitgeverij Komma, 98-115. https://www.uitgeverijkomma.nl/fotografie/music-brings-ustogether/

Bilda, Z., Edmonds, E., \& Candy, L. (2008). Designing for creative engagement. Design Studies, 29(6), 525-540. https://doi.org/10.1016/j.destud.2008.07.009

Boal, A., \& McBride, C. A. (1985). Theatre of the Oppressed. New York: Theatre Communications Group.

Boom. (2020). Vision. Retrieved from https://boomfestival.org/boom2021/vision/ourprinciples/

Breel, A. (2015). Audience agency in participatory performance: a methodology for examining aesthetic experience. Participations: Journal of Audience \& Reception Studies, 12(1), 368387.

Bregler, C., Castiglia, C., DeVincezo, J., DuBois, R. L., Feeley, K., Igoe, T., ... Wright, B. (n.d.). Squidball: An Experiment in Large-Scale Motion Capture and Game Design. 12. 
Brown, S., \& Hutton, A. (2013). Developments in the real-time evaluation of audience behaviour at planned events. International Journal of Event and Festival Management, 4(1), 43-55. https://doi.org/10.1108/17582951311307502

Carpenter, L., 1993. Video imaging method and apparatus for audience participation. US Patent \#5210604, \#5365266.

Cerratto-Pargman, T., Rossitto, C., \& Barkhuus, L. (2014). Understanding audience participation in an interactive theater performance. Proceedings of the 8th Nordic Conference on Human-Computer Interaction Fun, Fast, Foundational - NordiCHI '14, 608-617. https://doi.org/10.1145/2639189.2641213

Clifton, P., Caldwell, J., Kulka, I., Fassone, R., Cutrell, J., Terraciano, K., Murray, J., \& Mazalek, A. (2013). Don't open that door: Designing gestural interactions for interactive narratives. Proceedings of the 7th International Conference on Tangible, Embedded and Embodied Interaction - TEI '13, 259. https://doi.org/10.1145/2460625.2460668

Dialtones: A Telesymphony (Excerpts, 2001) on Vimeo. (n.d.). Retrieved May 15, 2019, from https://vimeo.com/4166428

Dourish P. (2001). Where the Action Is: the foundations of embodied interaction. doi:10.7551/mitpress/7221.001.0001

Foster, S. L. (2011). Choreographing empathy: Kinesthesia in performance Routledge.

Gaver, W., \& Höök, K. (2017). What makes a good CHI design paper? Interactions, 24(3), 20-21. https://doi.org/10.1145/3076255 
Gupta, S., Tanenbaum, T. J., \& Tanenbaum, K. (2019). Shiva's Rangoli: Tangible Storytelling through Diegetic Interfaces in Ambient Environments. Proceedings of the Thirteenth International Conference on Tangible, Embedded, and Embodied Interaction, 65-75. https://doi.org/10.1145/3294109.3295635

Harley, D., Chu, J. H., Kwan, J., \& Mazalek, A. (2016). Towards a Framework for Tangible Narratives. Proceedings of the TEI '16: Tenth International Conference on Tangible, Embedded, and Embodied Interaction - TEI '16, 62-69. https://doi.org/10.1145/2839462.2839471

Hassib, M., Schneegass, S., Henze, N., Schmidt, A., \& Alt, F. (2018). A Design Space for Audience Sensing and Feedback Systems. Extended Abstracts of the $2018 \mathrm{CHI}$ Conference on Human Factors in Computing Systems - CHI '18, 1-6. https://doi.org/10.1145/3170427.3188569

Hook, J., McCarthy, J., Wright, P., \& Olivier, P. (2013). Waves: Exploring idiographic design for live performance. Proceedings of the SIGCHI Conference on Human Factors in Computing Systems - CHI'13, 2969. https://doi.org/10.1145/2470654.2481412

Kirby, A. (2006). "The Death of Postmodernism and Beyond." Philosophy Now 58. http://www.philosophynow.org

Lakoff, G. T. (1987). Fire and Dangerous Things: What Categories Reveal about the Mind. Laurel, B. (1991). Computers as Theatre. Addison-Wesley. 
Lotto, B. (2019). “How we experience awe and why it matters.” TED: Ideas worth spreading. https://www.ted.com/talks/beau_lotto_and_cirque_du_soleil_how_we_experience_awe_a nd_why_it_matters

Malone, G. P., Pillow, D. R., \& Osman, A. (2012). The General Belongingness Scale (GBS): Assessing achieved belongingness. Personality and Individual Differences, 52(3), 311316. https://doi.org/10.1016/j.paid.2011.10.027

Maynes-Aminzade, D., Pausch, R., \& Seitz, S. (2002). Techniques for Interactive Audience Participation. 6.

Patsalidis, S. (2013). Audience Participation and the Theatre's Role in Post-Postmodernity. Critical Stages, Scènes Critiques http://www.critical-stages.org/9/audience-participationand-the-theatres-role-in-the-age-of-post-postmodernity-greece/\#end1

Pollice Verso. (n.d.). Retrieved May 21, 2019, from http://penelope.uchicago.edu/ grout/encyclopaedia_romana/gladiators/polliceverso.htl

Punchdrunk (2003). Sleep No More.

Ryan, M-L. (2001). Beyond Myth and Metaphor: The Case of Narrative in Digital Media. The International Journal of Computer Game Research, 1(1). http://gamestudies.org/0101/ryan/

Sang Won Lee and Aaron Willette. 2019. Crowd in C. In Proceedings of the 2019 on Creativity and Cognition (C\&C '19). ACM, New York, NY, USA, 425-431. DOI: https://doi.org/10.1145/3325480.3329178 
Stappers, Pieter Jan, \& Giaccardi, Elisa. (2014). “43. Research Through Design”. The Encyclopedia of Human-Computer Interaction (2nd ed.) https://www.interactiondesign.org/literature/book/the-encyclopedia-of-human-computer-interaction-2nded/research-through-design

Striner, A., Azad, S., \& Martens, C. (2018). A Common Framework for Audience Interactivity. ArXiv:1710.03320 [Cs]. http://arxiv.org/abs/1710.03320

Tan, L., \& Chow, K. (2018). An Embodied Approach to Designing Meaningful Experiences with Ambient Media. Multimodal Technologies and Interaction, 2(2), 13. https://doi.org/10.3390/mti2020013

TED. (2019, May 4). Mind-blowing sculptures that fuse music and technology: Es Devlin. [Video]. YouTube. https://www.youtube.com/watch? $\mathrm{v}=\mathrm{CeOadxT7kPA \& feature=youtu.be}$

Teevan, J., Liebling, D., Paradiso, A., Garcia Jurado Suarez, C., von Veh, C., \& Gehring, D. (2012). Displaying mobile feedback during a presentation. Proceedings of the 14th International Conference on Human-Computer Interaction with Mobile Devices and Services - MobileHCI '12, 379. https://doi.org/10.1145/2371574.2371633

TweetDreams. (n.d.). Retrieved May 15, 2019, from https://ccrma.stanford.edu/groups/tweetdreams/

Wang, C., Geelhoed, E. N., Stenton, P. P., \& Cesar, P. (2014). Sensing a live audience. Proceedings of the SIGCHI Conference on Human Factors in Computing Systems, 1909-1912. https://doi.org/10.1145/2556288.2557154 
Weitzner, N., Freeman, J., Garrett, S., \& Chen, Y.-L. (n.d.). massMobile - an Audience Participation Framework. 4.

Zhang, L., Bryan-Kinns, N., \& Barthet, M. (2018). Symphony : Creative Participation for Audiences of Live Music.

Zimmerman, E. (2004). Narrative, interactivity, play, and games: Four naughty concepts in need of discipline. MIT Press. 